\title{
The impact of life skills education on adolescent sexual risk behaviors
}

Robert Magnani

Kate Macintyre

Ali Mehyrar Karim

Lisanne Brown

Paul Hutchinson

Follow this and additional works at: https://knowledgecommons.popcouncil.org/departments_sbsr-hiv How does access to this work benefit you? Let us know!

\section{Recommended Citation}

Magnani, Robert, Kate Macintyre, Ali Mehyrar Karim, Lisanne Brown, and Paul Hutchinson. 2003. "The impact of life skills education on adolescent sexual risk behaviors," Horizons Research Summary. Washington, DC: Population Council. 


\section{Hgrizons}

\section{The Impact of Lif e Skil I S Education on Adol escent Sexual Risk Behaviors}

$n$ response to the escalating $\mathrm{HIV} / \mathrm{AIDS}$ epidemic, in 1998 the South African $M$ inistry of Education mandated implementation of a comprehensive life skills education program in all secondary schools by 2005. The L ife Skills Programme aims to increase knowledge and develop skills to help youth protect themselves from H IV infection and to safeguard their reproductive health. Although it is too early to assess the long-term impact of this initiative, the phased implementation of life skills education provides an opportunity to assess short-term impact.

To measure the effects of exposure to topics within the life skills curriculum on sexual and reproductive health knowledge and behaviors among youth, the $U$ niversity of $\mathrm{N}$ atal-D urban School of Development Studies, H orizons, The Population Council's Policy Research Division, and Tulane U niversity undertook a prospective study in KwaZulu $\mathrm{N}$ atal Province, South Africa, from 1999 to 2001. This summary considers the impact of the life skills program on a population-based sample of youth in two districts in the province. D uring the same time period, another $\mathrm{H}$ orizons study evaluated the impact of the course among ninth-grade students attending schools in K waZulu $\mathrm{N}$ atal where the course was taught. ${ }^{1}$

${ }^{1}$ See Reddy, P. et al. 2003. "Programming for H IV Prevention in South African Schools," Horizons Research Summary. Washington, D.C.: Population Council.

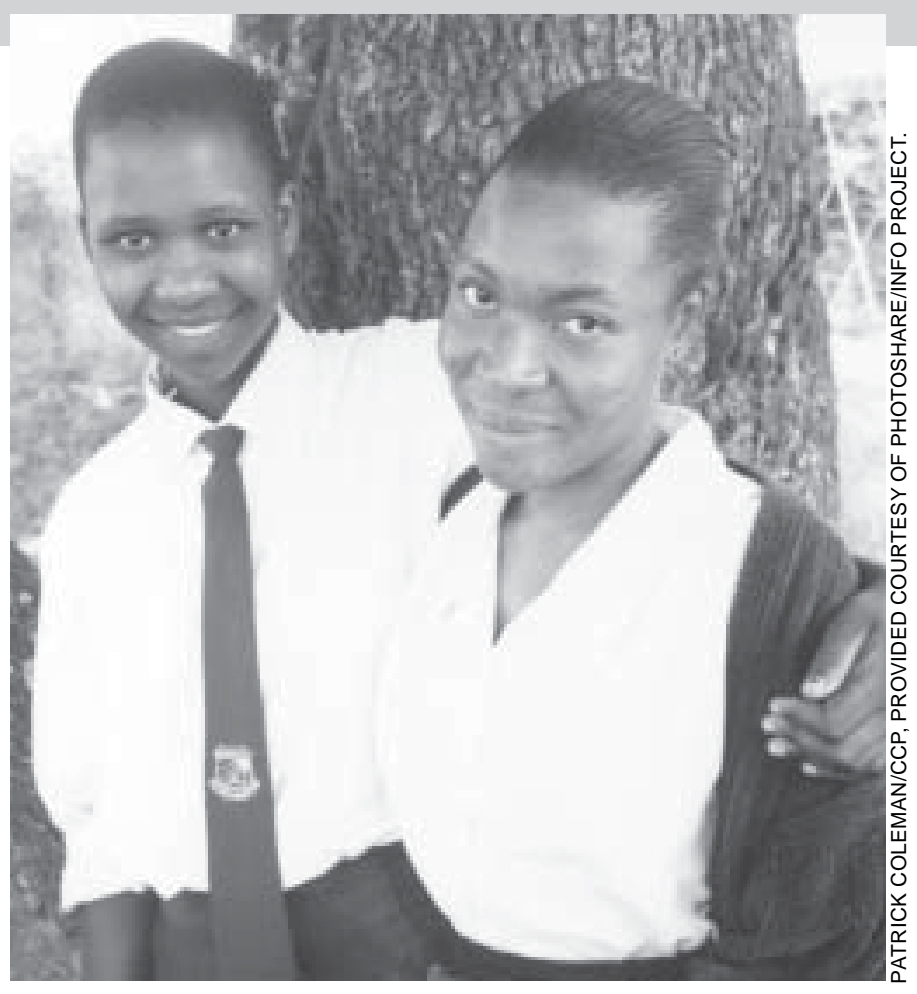

\section{Study Site and Sampling Design}

Two administrative areas in KwaZulu $\mathrm{N}$ atal, Durban $M$ etro and M tunzini M agisterial districts, were purposively selected. Within each area, all youth 14 to 22 years old residing in a segmented probability sample of $C$ ensus Enumeration Areas (CEAs) were interviewed in the Wave 1 survey (1999). In Wave 2 (2001), all youth 14 to 24 years old residing in the same CEAs were included in the survey, including 2,222 of the 3,052 youth also interviewed in Wave 1. The analysis in this report is based on the 2,222 youth who were interviewed at both Wave 1 and Wave 2 (see Table 1 for background characteristics). 
Table 1 Percent distribution of respondents

by background characteristics $(n=2,222)$

\begin{tabular}{lr}
\hline Age at Wave 1 & 58 \\
14-18 & 42 \\
$19-22$ & \\
Sex & 46 \\
$\quad$ Male & 54 \\
$\quad$ Female & \\
Population group & 77 \\
$\quad$ African & 18 \\
Asian & 5 \\
Other (white, Colored) & \\
Residence & 78 \\
$\quad$ Urban & 22 \\
$\quad$ Rural & \\
Education & 16 \\
$\quad$ Not in school during both waves & 62 \\
In school during both waves & 19 \\
In school at wave 1, but not wave 2 & 3 \\
In school at wave 2, but not wave 1
\end{tabular}

\section{Methods}

Because the South Africa life skills initiative aimed to be a full coverage program, it was not possible to use a randomized control design to measure program impact. This is because schools initiated life skills education at different speeds and intensities. The study therefore measured young people's recall of topics from their school training and assessed the differences in sexual and reproductive health knowledge and behaviors, given that these young people were differentially exposed to the topics. This is called measuring the dose-response relationship between indicators of exposure to education and sexual-reproductive health knowledge and behaviors. All the multivariate models used in this study control for unmeasured factors using a variable for survey year. A significant effect for this survey year variable was found for many of the models and may be interpreted as reflecting the combined effects of maturation of youth, exposure to sources of information other than life skills education, and general secular trends.

Exposure to life skills was measured by respondents' report of having been taught about 11 key sexual and reproductive health topics during school classes (see box).
Behavioral outcomes included:

- Sexual abstinence to either postpone first sex (delay initiation) or, for those already initiated, reduce risk through secondary abstinence.

- No more than one sex partner in the past 12 months.

- Condom use (i.e., condom use at first sex, condom use at last sex, and consistency of condom use with all partners).

Separate analyses were conducted by sex, race, and age.

\section{Key Findings}

M ost study respondents have been exposed to at least some life skills education. Youth report a substantial increase in exposure to life skills over the two-year period. By 2001, most respondents had been exposed to at least some information and support for skills development to help them reduce their risk. The largest gains in exposure were observed among African and Asian students. African youth remain somewhat underserved in 2001 in comparison with those from other races, although the gap has narrowed considerably since 1999.

\section{Knowledge about HIV prevention topics increased, particularly among Africans, males, and younger youth. Gains in sexual and reproductive health-related knowledge were in}

\section{Life Skills Topics}

- Reproductive biology

- Human growth and development and the life cycle

- Understanding sexuality/relationships with the opposite sex

- Self-esteem, assertiveness, and decision making

- Relationships: communication and negotiation with your partner

- HIV/AIDS transmission and prevention/condom use

- HIV/AIDS: looking after people with AIDS

- STDs: prevention and symptoms

- Drugs and alcohol

- Contraception/preventing unwanted pregnancy

- Violence and sexual abuse - child abuse, incest, rape, and coercion 
general modest and uneven, although substantial gains were noted on a number of key topics in H IV prevention. Significant effects of exposure to life skills education are observed for three knowledge outcomes: knowledge of HIV modes of transmission, knowledge of ST Is other than $\mathrm{HIV}$, and number of contraceptive methods known. In general where significant effects were observed, the effects are more consistent for males than females, for Africans vs. youth of other races, and for younger vs. older youth.

\section{Youth exposed to life skills education are more} likely to use condoms, but there was no effect on other key behaviors. Confidence to use condoms effectively and actual use have increased for many adolescents. But there is no evidence from the data that youth are delaying initiation of sex or reducing their number of partners as a result of life skills education.

- Exposure to life skills education showed an effect on confidence to obtain condoms among females, Africans, and 19-22 yearolds. For the self-efficacy of condom use outcome, exposure effects are widespread across most sub-groups of youth.

- O verall those exposed to life skills education were significantly more likely to show an increase in reported condom use at first sex and last sex. Females, Africans and younger youth exposed to the program were more likely to report condom use at first sex. Africans and younger youth were more likely to report condom use at last sex.
- Figure 1 is based on multivariate models and shows the association between the degree of exposure to life skills among respondents and condom use at first sex for those who had their first sex after the Wave 1 survey, and condom use at last sex for those sexually experienced. "Present level of exposure" refers to the average number of life skills topics recalled by respondents. "No exposure" refers to the hypothetical situation of the absence of the program and "maximum exposure" refers to the hypothetical situation in which all youth received instruction in all 11 life skills topics. The magnitude of program impact is, while statistically significant, generally modest. For example, the models suggest that if life skills education had been fully implemented by 2001 (i.e., all sexually experienced students had been exposed to all 11 life skills topics in the 2001 school year), condom use at last sex among males would have been 7 percentage points higher ( 65 vs. 58 percent) than the observed levels.

- Although there are modest increases in secondary abstinence (at the bivariate level) among males and females, the results showed no impact on this behavior among those exposed to life skills. H owever, the survey year effect was significant and positive, suggesting that the increased prevalence of secondary abstinence was due to influences other than school-based life skills education.

- Exposure to life skills education also had no effect on the number of partners reported in the last 12 months.

Figure 1 Association between exposure to life skills and condom use

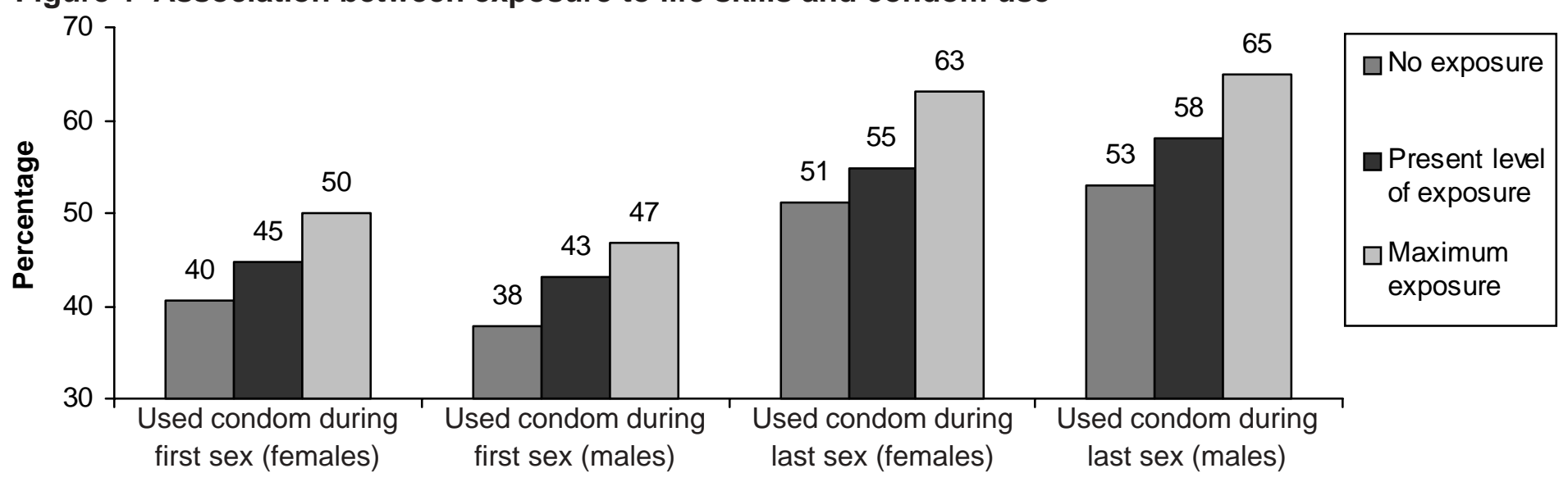

Note: Controls for socioeconomic status 


\section{Conclusions and Program Implications}

The findings indicate substantial short-to-medium-term effects of exposure to life skills education on certain areas of H IV/ STI-related knowledge, confidence to use condoms, and condom use behavior. $\mathrm{H}$ owever, no effects on age at sexual debut or partner reduction were observed. D espite significant increases in condom use at last sex, these levels are only moderate (less than 60 percent for those reporting sexual activity), and thus many youth remain at high risk. Further research is needed to assess whether the observed effects are transitory or long-term in nature, whether the observed behavioral changes have an impact on H IV infection rates among youth, and whether the full implementation of life skills education in all schools in KwaZulu $\mathrm{N}$ atal can broaden program impact to also include other sexual behaviors such as delay of sexual initiation and secondary abstinence. The results of this study have implications for the improvement of life skills education in South Africa.

\section{Life skills education should equally emphasize all methods of preventing pregnancy and} transmission of STIS and HIV. The results of this study suggest that students who are exposed to life skills education have increased use of condoms, but there was no impact of exposure to life skills education on other sexual behaviors such as age at sexual initiation, abstinence, and number of partners. This may be because the condom use messages are the only ones that students retain or life skills education is focusing on condom use and less on other means of preventing pregnancy, STIS, and HIV.
Life skills education should support secondary abstinence, which is already increasing due to other factors. The results show that secondary abstinence has increased during the study time period. $\mathrm{H}$ owever, this change was not attributable to exposure to life skills education. Youth appear to be practicing secondary abstinence in response to other messages or changes in society, and the Life Skills Programme should help reinforce those changes.

\section{The gap in exposure to life skills education among the different racial groups needs to be further narrowed. In particular, life skills education for black populations needs to be strengthened. While this study shows significant improvement in this area over the two years of the study, the gap persists.}

\section{Life skills education should be tailored to the needs of different groups. This study revealed} important differences in sexual behaviors by age, sex, and population group. To the extent possible, life skills education should provide appropriate knowledge and skills to these different groups. ?

July 2003

Transitions to Adulthood study team members are Julian $M$ ay and $N$ tsiki $M$ anzini, $U$ niversity of $N$ atal, $D$ urban; Carol Kaufman (now with U niversity of Colorado $\mathrm{H}$ ealth Sciences Center), Naomi Rutenberg, and Kelly $\mathrm{H}$ allman, Population Council; L isanne Brown, Ali M ehyrar Karim, Bob M agnani, Kate $M$ acintyre, and Paul $H$ utchinson, Tulane U niversity; Stavrou Stavros, Anthea D allimore, and Ruanne Fensham, DRA D evelopment. Analysis was performed by Robert M agnani, Ali M ehyrar Karim, Kate $M$ acintyre, Lisanne Brown, and Paul H utchinson.

Suggested citation: M agnani, R. et al. 2003. "The I mpact of Life Skills Education on Adolescent Sexual Risk Behaviors," H orizons Research Summary. Washington, D.C.: Population Council.

\section{Hgrizons}

Population Council/Horizons

Communications Unit

4301 Connecticut Avenue, NW

Suite 280

Washington, DC 20008
Population Council

Tel: 202-237-9400

Fax: 202-237-8410

horizons@pcdc.org

www. popcouncil.org/ horizons usaw This publication was made possible through support provided by the Global Bureau of Health/HIV-AIDS, U.S

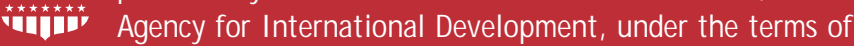
Award No. HRN-A-00-97-00012-00. The opinions expressed herein are those of the authors and do not necessarily reflect the views of the U.S. Agency for I nternational Development. 


\section{Secondary School Principals Report Dramatic Expansion of LifE SKILLS}

In 1999, 277 principals from all of the secondary schools in the Durban $M$ etro and $M$ tunzini districts in KwaZulu $\mathrm{N}$ atal Province were interviewed about the teaching of life skills education in their schools. The interviewers returned to the schools in 2001 to re-interview the principals, noting whether the same principal was in charge. The results presented are based on 257 matched pairs. Response rates at both times were greater than 95 percent. The surveys asked about the characteristics of the schools, the comprehensiveness and coverage of life skills education, demographic information about the respondents, and their attitudes about reproductive health issues and about teaching sexuality in school. No data were collected on the quality of teaching of the life skills curriculum.

\section{Key Findings}

\section{M ore than 90 percent of schools offered life}

skills education in 2001, a significant increase from 1999. Life skills education coverage increased dramatically between 1999 and 2001, when the percentage of schools that taught any of the 11 life skills topics,

according to principals' reports, rose from 60 percent to 93 percent. There is an even greater increase in the percentage of schools that teach the six core life skills (contraception/ pregnancy prevention, H IV prevention including condom use, care for people living with HIV and AIDS, prevention and symptoms of ST Ds, relationships and negotiation, and self-esteem/ decision making), from 20 percent in 1999 to 66 percent in 2001. The percentage of schools with teachers trained for life skills increased from 76 percent to 94 percent.
Findings from the larger T ransitions study of adolescents between the ages of 14 to 22 support the increase in life skills education that was found in the principals' data. Adolescents reported higher levels of exposure to the core life skills topics in the 2001 survey as compared to the 1999 survey. Instruction in at least one format (either as an independent subject, integrated into other courses, or as a special presentation) of the following topics increased by 15 percent or more: STD prevention and symptoms, HIV prevention, care for people living with HIV and AIDS, relationships with the opposite sex, and selfesteem/ decision making. These improvements were similar for males and females.

\section{Principals showed greater support for adolescent girls to attend school during pregnancy and after giving birth. Fewer principals said that pregnant students should be asked to leave school (from 54 percent in 1999 to 38 percent in 2001 and a greater percentage of}

\section{Life Skills Topics}

- Reproductive biology

- Human growth and development and the life cycle

- Understanding sexuality/relationships with the opposite sex

- Self-esteem, assertiveness, and decision making

- Relationships: communication and negotiation with your partner

- HIV/AIDS transmission and prevention/condom use

- HIV/AIDS: looking after people with AIDS

- STDs: prevention and symptoms

- Drugs and alcohol

- Contraception/preventing unwanted pregnancy

- Violence and sexual abuse - child abuse, incest, rape, and coercion 
Figure 1 Changes in provision of life skills, by principals' perception of students' risk status

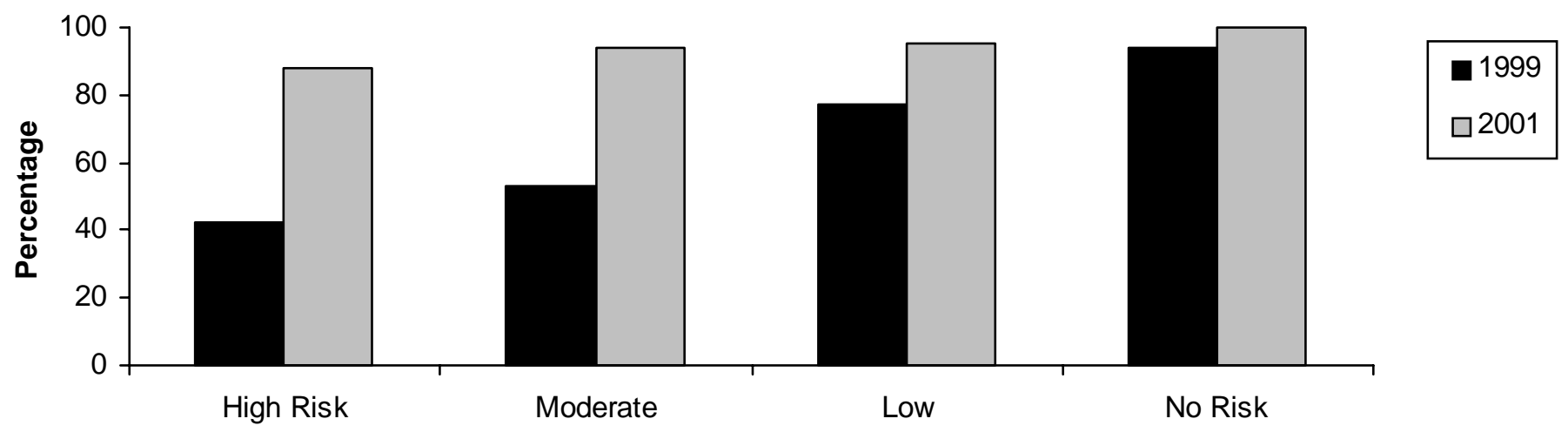

principals said that teenage students should be allowed to return after giving birth (from 88 percent in 1999 to 95 percent in 2001). Both of these changes were statistically significant $(p<0.05)$.

Several other items also changed, but not significantly: Fewer said that virginity testing is a good way to discourage sex (41 percent in 1999 and 38 percent in 2001) and that students who are H IV-positive should not be allowed in school (9 percent in 1999 to 7 percent in 2001).

\section{African, Asian, and mixed-race schools and schools with high-risk student bodies achieved the greatest expansion of life skills} instruction. Schools that are predominantly African, Asian, or racially mixed show the greatest increases in providing instruction in any life skills area and in the core life skills topics. In 1999, those schools where the principal perceived the students to be at high risk of pregnancy and HIV infection were significantly less likely to offer life skills education than schools where the students were not at risk. By 2001, according to principal reports, schools with high-risk students showed the greatest improvement in offering life skills education (Figure 1).

\section{Discussion}

By 2001, most secondary school students in the D urban $M$ etro and $M$ tunzini districts had been exposed to information to help them reduce their risk of pregnancy and H IV/ ST Is. This represents an important increase since 1999. The greatest expansion of life skills instruction was found in the African, Asian, and mixed-race schools and in schools where the principals perceived the student bodies to be at high risk. D espite the overall positive picture, more resources are still needed for schools lagging behind or that do not currently offer any life skills education.

July 2003

Transitions to Adulthood study team members are Julian $M$ ay and $N$ tsiki M anzini, U niversity of $N$ atal, D urban; $C$ arol Kaufman (now with $U$ niversity of Colorado $H$ ealth Sciences Center), Naomi Rutenberg, and Kelly $\mathrm{H}$ allman, Population Council; Lisanne Brown, Ali M ehyrar Karim, Bob M agnani, $K$ ate $M$ acintyre, and Paul $H$ utchinson, T ulane $U$ niversity; Stavrou Stavros, Anthea D allimore, and Ruanne Fensham, DRA D evelopment. Analysis was performed by Robert Magnani, Ali M ehyrar Karim, Kate M acintyre, Lisanne Brown, and Paul Hutchinson.

Suggested citation: Brown, L. et al. 2003. "Secondary School Principals R eport D ramatic Expansion of L ife Skills," H orizons Research Summary. Washington, D.C.: Population Council.

\section{Hqrizons}

Population Council/ Horizons

Communications Unit

4301 Connecticut Avenue, NW

Suite 280

Washington, DC 20008

\section{(1) Population Council}

Tel: $202-237-9400$

Fax: 202-237-8410

horizons@pcdc.org www. popcouncil.org/horizons
Horizons conducts global operations research to improve HIV/ AI DS prevention, care, and support programs. Horizons is implemented by the Population Council in partnership with the International Center for Research on Women (ICRW), the Program for Appropriate Technology in Health (PATH), the International HIV/ AI DS Alliance, Tulane University, Family Health International, and J ohns Hopkins University.

Usauv This publication was made possible through support provided by the Office of HIV/AIDS, U.S. Agency for International Development, under the terms of Award No. HRN-A-00-97-00012-00. The opinions expressed herein are those of the authors and do not necessarily reflect the views of the U.S. Agency for International Development. 